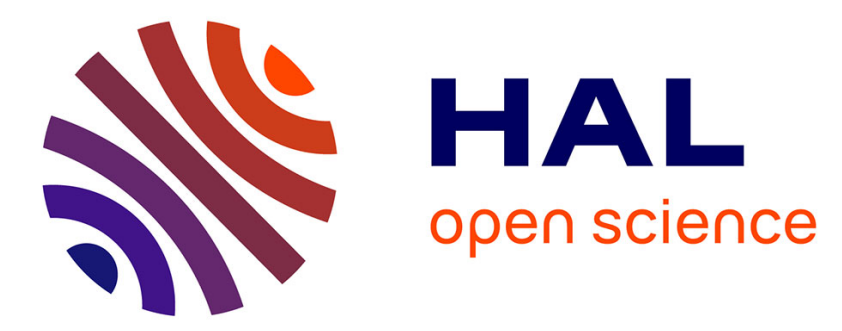

\title{
Emerging Community Energy Ecosystems: Analysis of Organizational and Governance Structures of Selected Representative Cases
}

\author{
Kankam O. Adu-Kankam, Luis Camarinha-Matos
}

\section{To cite this version:}

Kankam O. Adu-Kankam, Luis Camarinha-Matos. Emerging Community Energy Ecosystems: Analysis of Organizational and Governance Structures of Selected Representative Cases. 10th Doctoral Conference on Computing, Electrical and Industrial Systems (DoCEIS), May 2019, Costa de Caparica, Portugal. pp.24-40, 10.1007/978-3-030-17771-3_3 . hal-02295242

HAL Id: hal-02295242

https://hal.inria.fr/hal-02295242

Submitted on 24 Sep 2019

HAL is a multi-disciplinary open access archive for the deposit and dissemination of scientific research documents, whether they are published or not. The documents may come from teaching and research institutions in France or abroad, or from public or private research centers.
L'archive ouverte pluridisciplinaire HAL, est destinée au dépôt et à la diffusion de documents scientifiques de niveau recherche, publiés ou non, émanant des établissements d'enseignement et de recherche français ou étrangers, des laboratoires publics ou privés.

\section{(c)(1)}

Distributed under a Creative Commons Attribution| 4.0 International License 


\title{
Emerging Community Energy Ecosystems: Analysis of Organizational and Governance Structures of Selected Representative Cases
}

\author{
Kankam O. Adu-Kankam ${ }^{1,2}$, and Luis M. Camarinha-Matos ${ }^{1}$ \\ ${ }^{1}$ Nova University of Lisbon, Faculty of Sciences and Technology and \\ UNINOVA - CTS, Campus de Caparica, 2829-516 Monte Caparica, Portugal \\ ${ }^{2}$ School of Engineering, University of Energy and Natural Resources (UENR), \\ P. O. Box 214, Sunyani, Ghana \\ E-mails: kankamadu@gmail.com, cam@uninova.pt
}

\begin{abstract}
The quest to decarbonize and decentralize the current power grid has enabled high penetration of Distributed Energy Resources at the edge of the distribution network. The diversity, complexity and growing numbers of these energy resources currently pose a challenge to managing them. This has resulted in the emergence of various energy ecosystems which use diverse communitybased organizational strategies and initiatives as forms of management techniques. There are also corresponding business models and governance structures that are innovative and technologically disruptive to the operations of the current grid. An analysis of five representative cases of these Renewable Energy Communities is performed using real-life projects as case studies. The focus areas considered in this study included organizational and governance structures, roles, and the relationship between key stakeholders/owners, how these ecosystems interact with the power grid, and the role of collaborations. The outcome of the study revealed that each category of ecosystem has similar organizational and governance structures although they may differently be constituted. In terms of ownership, energy cooperative, municipalities, and communities were found to own a greater share of these energy resources. Furthermore, most of these ecosystems were found to interact with the grid by supplying excess energy from the community to the power grid whilst others operate in isolation from the grid. Apart from one case, all the others showed elements of collaborations as an integral component of their mode of operations.
\end{abstract}

Keywords: Renewable energy communities, Energy cooperatives, Collaborative networks, Collaborative energy ecosystems.

\section{Introduction}

According to [1], the future of energy rests on the foundations of cleaner, distributed, and intelligent networks of power. This notion is being advanced by the rapid innovations that are emerging at the edge of the power grid, which is driving a paradigm shift, that is transforming the power network towards the 5D (digitalization, 
decentralization, decarbonization, democratization, and deregulation) [2]. These evolving technologies are characterised by high penetration of Distributed Energy Resources (DERs), artificial intelligence, cloud computing, blockchain technology and a host of other cutting-edge applications and services [3] that are facilitating these transformations in alignment with current trends on Industry 4.0 [4]. According to recent developments, DER asset owners, property owners (land and building) and other entities have become economic participants and key players in the way energy is generated, distributed, and consumed. Additionally, new stakeholders, such as individual prosumers, local community members, and local governments are also emerging with community-based energy concepts that are transforming and enhancing the energy value-chain in diverse ways. These developments are driving the rapid proliferation of new energy models such as Renewable Energy Communities (RECs), Peer to peer energy sharing, Integrated community energy systems, Energy hubs, IEEE smart villages, etc., which are kinds of emerging "energy ecosystems". These ecosystems fit into a broader framework of upcoming concepts like collaborative economy or sharing economy which involve a more decentralized approach to the exchange of goods and services. To compliment the rapid evolution of these concepts, scientific disciplines such as Collaborative Networks are emerging [5], [6], [7] which provide a comprehensive body of knowledge, including reference models [8] that enhances the understanding of collaborations within these emergent domains. Additionally, these disruptive concepts are redefining market relationships between traditional sellers and buyers and therefore expanding models of transaction and consumption, which invariably are impacting business models across diverse ecosystems, which includes energy [9].

This work focuses on the analysis of five emerging RECs using representative reallife cases. A sixth case, which is "Energy hubs", is mentioned briefly in this work but without any detailed analysis because the concept is currently at a theoretical stage. Three research questions are used for this study. These are: (1) RQ1. How are these RECs organised? (which can include as sub-questions: RQ1A. What are the roles and responsibilities? RQ1B. How are these RECs governed? RQ1C. What relationship exists between roles?); (2) RQ2. How do these RECs interact with the power grid? and (3) RQ3. What role does collaborations play in these RECs?

The outline of this paper is as follows: Section one introduces the research concepts and related research questions. Section two describes the relationship of this work to the conference theme, followed by section three which focuses on the case study. The main contribution of this work is described in section four.

\subsection{Related Works}

This section of related works has a narrow scope because it is intended to address the related works in the context of the on-going research as described in section four. It is therefore focused on prosumers within RECs, also referred to as Prosumer Community Groups (PCGs). In [10], the authors performed a literature review to determine the evolution and future directions of key issues, challenges, and opportunities in PCGs. In this review, the authors proposed eight future trends and current research gaps in the area. Another related work presented in [11] explored the concept of PCGs and 
proposed a novel framework for the definition and formation of these groups by clustering prosumers based on their energy behaviour. Another dimension of this concept was explored by Rathnayaka et el in [12]. Here the authors propose a goaloriented prosumer community group notion, that adopts the VPP concepts leading to a sustainable energy sharing process. From a different perspective, [13] organised prosumers into virtual clusters so that they could participate in the energy market as a single entity enabling a reduced total energy cost due to forecasting inaccuracies. In [14], a framework to integrate prosumer communities into the existing day-ahead and intraday markets is introduced. The authors proposed the Smart elecTricity Exchange Platform as an interface between the wholesale energy markets and prosumer communities. Furthermore, a comparative study is conducted in [15] to assess the technical and economic feasibility of household energy storage and centralized community energy storage.

\section{Relationship to Innovation in Industrial and Service Systems}

The next industrial revolution (Industry 4.0) and related services, characterized by digitalization of goods and services, resulting in enhanced value chains, and disruptive business models, require corresponding energy systems which are digitalized, distributed, decarbonized, democratized, and smart [4], [16]. According to the United Nations Industrial Development Organization, to achieve the international climate change mitigation targets, the industrial sector, which accounts for approximately one-third of global final energy use and $40 \%$ of global energy-related CO2 emissions (OECD/IEA 2009) [16], must reconsider the kinds and sources of energy they consume. Therefore, the transition towards more sustainable energy ecosystems and the digital transformation of industries could mutually benefit from each other by offering solutions, that help to optimise the integration of renewable/sustainable forms of energy on an industrial scale.

\section{Case Study}

\subsection{Integrated Community Energy Systems/Solutions (ICES)}

According to Koirala et al. (2016), there is no single definition nor typology to describe ICESs. However in general terms, they are tailored (in technology and size) to meet the needs of the respective community [17]. By taking a more holistic approach to energy demand and supply, ICES provide a good alternative to energy management for the benefit of an entire community. For instance, waste heat from industry could be used to heat buildings in community and activities that encourage energy conservation is also practiced. ICES approach to energy management help to achieve better overall energy savings in a community. An ICES community can be established in a rural area, a neighbourhood or a large city. 
Table 1. Case 1: Feldheim, Germany [18], [19]

\begin{tabular}{|c|c|c|c|c|c|}
\hline \multirow[b]{2}{*}{$\begin{array}{c}\text { Key } \\
\text { stakeholders }\end{array}$} & \multicolumn{3}{|c|}{ Roles } & \multirow[b]{2}{*}{$\begin{array}{l}\text { Governance } \\
\text { structure }\end{array}$} & \multirow[b]{2}{*}{$\begin{array}{l}\text { Grid } \\
\text { interaction }\end{array}$} \\
\hline & Key roles & $\begin{array}{c}\text { Energy } \\
\text { resource } \\
\text { ownership }\end{array}$ & $\begin{array}{c}\text { Characteristic \& } \\
\text { and relationship } \\
\text { between roles }\end{array}$ & & \\
\hline $\begin{array}{l}\text { Feldheim New } \\
\text { Energy Forum } \\
\text { Foundation }\end{array}$ & $\begin{array}{l}\text { 1. Project financiers } \\
\text { 2. Management body } \\
\text { 3. Education and } \\
\text { information }\end{array}$ & \multirow{5}{*}{$\begin{array}{l}\text { Community } \\
\text { owned } \\
\text { assets: } \\
\text { 1. Wind } \\
\text { turbines } \\
2 . \text { PV } \\
\text { modules } \\
\text { 3. Biogas } \\
\text { 4. Biomass } \\
\text { 5. CHP } \\
\text { 6. Lithium- } \\
\text { ion battery } \\
\text { system }\end{array}$} & \multirow{5}{*}{$\begin{array}{l}\text { Characteristics } \\
\text { of roles: } \\
\text { - Public } \\
\text { private } \\
\text { partnership. } \\
\text { Relationship } \\
\text { between roles: } \\
\text { - Distributed } \\
\text { systems with } \\
\text { centralized } \\
\text { management } \\
\text { and } \\
\text { hierarchical } \\
\text { governance }\end{array}$} & \multirow{5}{*}{$\begin{array}{l}\text { Governance } \\
\text { type: } \\
\text { Non-profit } \\
\text { self- } \\
\text { governance } \\
\text { Structure: } \\
\text { 1. Executive } \\
\text { Board } \\
\text { 2. General } \\
\text { assembly with } \\
\text { voting rights } \\
\text { 3. One } \\
\text { member one } \\
\text { vote }\end{array}$} & \multirow{5}{*}{$\begin{array}{l}\text { Send } 90 \% \text { of } \\
\text { energy } \\
\text { produced in } \\
\text { the } \\
\text { community } \\
\text { to the grid. } \\
\text { The village } \\
\text { uses only } \\
10 \% \text {. }\end{array}$} \\
\hline $\begin{array}{l}\text { Municipality of } \\
\text { Treuenbrietzen }\end{array}$ & $\begin{array}{l}\text { 1. Project financiers } \\
\text { 2. Project initiation } \\
\text { and implementation }\end{array}$ & & & & \\
\hline $\begin{array}{l}\text { Residents of } \\
\text { Feldheim and } \\
\text { Treuenbrietzen }\end{array}$ & $\begin{array}{l}\text { 1. Project financiers } \\
\text { 2. Centre of } \\
\text { excellence } \\
\text { 3. Energy consumers }\end{array}$ & & & & \\
\hline $\begin{array}{l}\text { Feldheim } \\
\text { Energiequelle } \\
\text { GmbH }\end{array}$ & $\begin{array}{l}\text { 1. Project initiation } \\
\text { and implementation } \\
\text { 2. Project managers }\end{array}$ & & & & \\
\hline $\begin{array}{l}\text { Farmers' } \\
\text { cooperative }\end{array}$ & $\begin{array}{l}\text { 1.Project financiers } \\
\text { 2. Land owners }\end{array}$ & & & & \\
\hline
\end{tabular}

Table 2. Case 2: Wildpoldsried, Germany [20], [21], [22],[23]

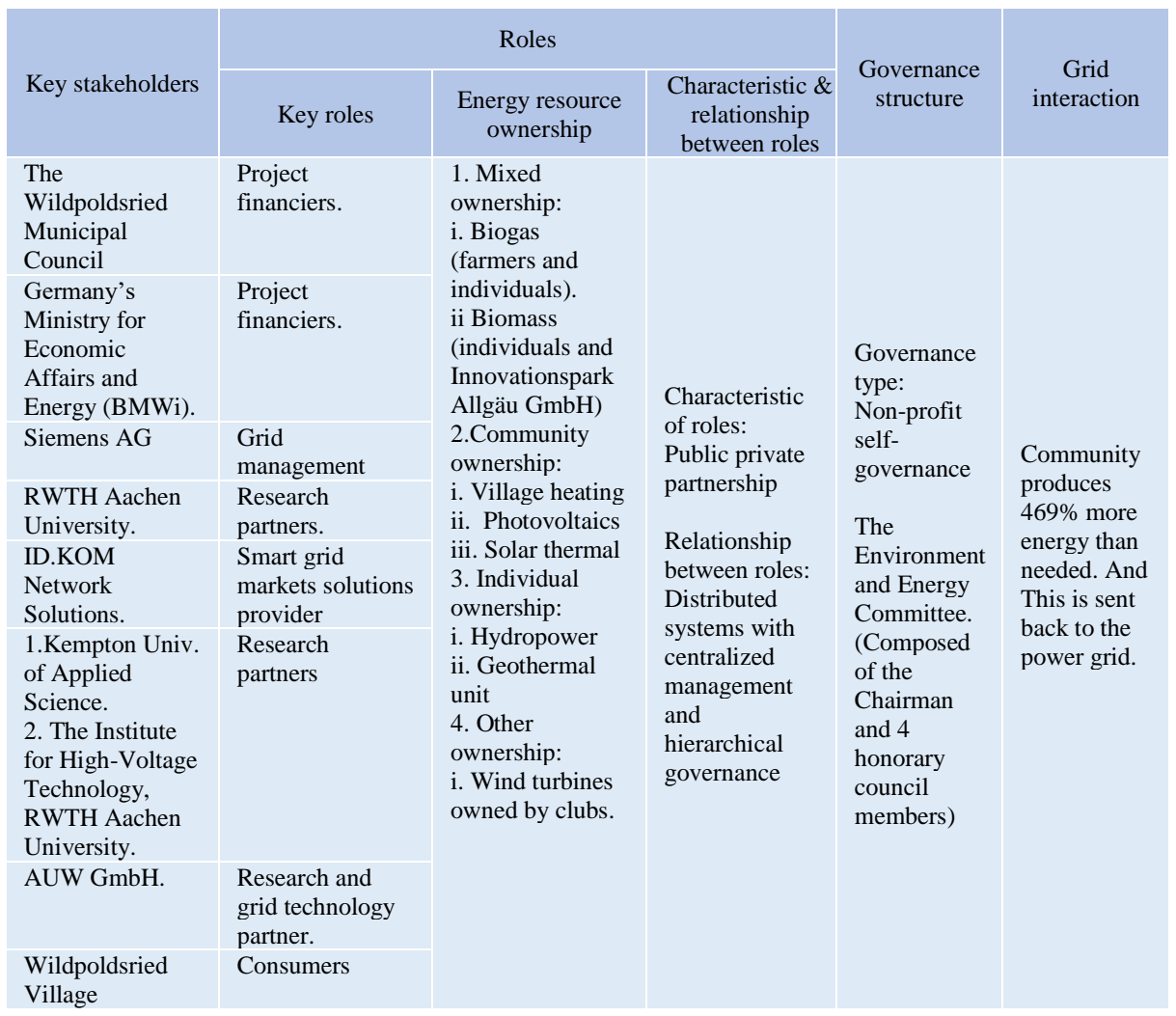




\section{Summary of ICES case study:}

RQ1. Organization

- Roles and responsibilities: The key roles found include project financiers who provide financial input into the projects. Other financial partners include non-profit organizations, governmental agencies and community-owned cooperatives. There is also strong involvement of utility companies and grid operators who provide grid management and research services. Other actors in the ecosystem include academic/research institutions who provide research and development support for the ecosystem and finally environmentally sustainable groups who advocate for sustainable communities and energy use (providing energy advice to members). The community is key consumer of the energy produced.

- Governance: Types seen in these ecosystems are predominantly non-profit, nongovernmental and self-governance. Board of directors are usually appointed to be managers of these energy ecosystems. The number of directors varies from case to case, however, there is a General Assembly that is constituted of the investors/community members and they all have equal voting rights which is: one man one vote, irrespective of the value/stake of their investment.

- Characteristics and relationships: Public private partnership. Distributed systems with centralized management and hierarchical governance is the relationship between key roles.

RQ2. Interaction with the power grid: In the cases considered, the community generates excess energy far beyond the demands of the community. This is sold to the power grid to generate revenue for community benefit. Some percentage of the revenue is re-invested in community projects whilst $5-10 \%$ is paid annually to investors as dividends. This possibility therefore makes these communities viable sources of long-term energy business investment.

RQ3. Role of collaboration: Collaborations between key stakeholder's results in the production of energy to meet the need of the community and the excess injected into the power grids. Stakeholders also collaborate to invest in social intervention projects such as conversion of street lights into energy saving LEDs, for the community using proceeds from energy sale.

\section{Limitation of ICES:}

- Communities vary in size, structure, resources, laws, and opportunities, which leads to a wide array of organizational possibilities and no standardized approach to planning and deploying an ICES system.

- Limited ownership and participation by individuals. Most of the energy resources in these energy ecosystems are usually owned by municipalities, or governments, utility companies, factories and energy cooperatives. This is because of the scope, scale and technological complexity for planning and deployment of these ecosystems makes it unattractive for individuals.

- Development of these projects are usually confronted by the NIMBY (Not in my back yard) syndrome, which often opposes the installation of solar PVs and wind turbine in these communities. 


\subsection{Shared Renewable Energy Facility (SREF)}

The Interstate Renewable Energy Council [24] defines a SREF as a facility that is located in or near the service territory of an Electricity Provider where the electricity generated by the facility is credited to participants of the facility. Typically, participating customers lease or purchase a share of the output of the facility. This facility may be owned by a utility company, a third party or participating customers [25]. As the facility generates electricity, participants receive a utility bill credit or direct payment, based on the electricity produced by their share of the facility. Current literature supports two types of SREF. These are: 1) Community shared solar, and 2) Community shared wind. Since the concepts and principles behind these two technologies are similar, this study will focus on only the first category.

Community Shared Solar. A study conducted in 2008 by the National Renewable Energy Laboratory found that only 22 to $27 \%$ of residential rooftop areas is suitable for hosting an on-site photovoltaic (PV) system [26]. Therefore, to expand access to solar power, a new business model that enables those with shaded roofs, and those who choose not to install a residential system on their home for financial or other reasons, to rent or purchase a share of a solar facility. In a community shared solar project, customers subscribe to the program by purchasing a share of its energy output (solar). This is achieved either through an upfront payment or through ongoing monthly payments. This allows subscribers to benefit from a central commercial-scale solar plant through virtual net energy metering [27]. Literature such as [26] describes three models of Community shared solar projects: 1) Utility-Sponsored Model, 2) Special Purpose Entity Model, and 3) Non-profit Model. Studied cases:

- Case 1: Westmill Solar Co-operative (Special Purpose Entity Model) [28], [29]

- Case 2: Bristol Energy Cooperative (Special Purpose Entity Model) [30], [31]

\section{Summary of Community shared Solar}

RQ1. Organization:

- Roles and responsibilities: These ecosystems are multi-stakeholder with diverse roles and responsibilities. Since these installations usually cover large parcels of land, land owners and local community/councils' have high stakes and play key ownership roles. Other emerging roles include partners for social marketing (e.g. Oggadoon) and advocacy groups like the Westmill Sustainable Energy Trust and the Climate Coalition play key roles to promote the sustainability of the energy community and climate change. Housing cooperation like Ambition Lawrence Weston are direct beneficiaries of the energy facility. In both cases considered, the facility is owned by the local cooperatives who are major consumers of the energy produced.

- Governance: The governance type here is also non-profit, non-governmental and self-governance. Just like the previous case in ICES, Board of directors are usually appointed to be managers of these ecosystems. The number of directors also varies from one case to another. However, there is a General Assembly that is constituted of the investors/community members and they all have equal voting rights which is one man one vote, irrespective of the value/stake of your investment.

- Characteristics and relationships: Public private partnership. Distributed systems with centralized management and hierarchical governance. 
RQ2. Interaction with the power grid: These ecosystems also inject excess power into the grid and receive revenue through Feed-in-tariffs.

RQ3. Role of collaboration: The community collaborates to share a common resource which is a community owned solar PV installation. They also collaborate to consume locally generated energy thereby reducing total reliance on the power grid.

\section{Limitations of shared renewable energy facilities}

- As an emerging concept, it is likely to face developmental, implementation and policy barriers. Again, the technical, financial and socio-economic potential as well as challenges may take a while to understand.

- High upfront investment cost and long-term return on investments makes it attractive only to customers who are willing to pay high premium for renewable energy use, which may exclude moderate to low income customers.

- Regulations framework for these ecosystems are currently weak or non-existent.

- Interest here is predominantly based on the financial gains for the investors and not to promote a resilient energy community.

\subsection{Community Microgrids (CM)}

According to the Clean Collation, a Community Microgrid (CM) is a coordinated local grid area served by one or more distribution substations and supported by high penetrations of local renewables [32]. Although linked to the main electric grid, during power outage a CM can isolate from the broader grid and provide renewables-driven backup power to critical facilities [33]. Considering the constant threats posed by natural disasters like hurricanes, wildfires, floods tsunamis and cyber-attacks which have the potential to completely knock down the entire electrical infrastructure makes this energy concept very attractive. A key feature of a CM is the ability to serve thousands of customers with local renewable energy while achieving economies-ofscale and providing renewables-driven power backup to critical facilities and services during grid outages [34]. In [32], the authors further explained that CM represents a new approach for designing and operating the electric grid. It is purposely designed to rely heavily on DERs to enable a more sustainable, secure, and cost-effective energy system while generally providing renewables-driven power backup for prioritized loads over indefinite durations. Potential and ideal sites for CM implementation may include critical infrastructures that are useful for evacuations, provision of shelter, recovery staging, and life-sustaining services. Studied cases:

- Case 1: Long Island Community Microgrid Project (LICMP), East Hampton, NY. [35], [36],[34], [37]

- Case 2: Montecito Community Microgrid Initiative [38], [39], [40]

\section{Summary of CM}

RQ1Organization:

- Roles and responsibilities: Key roles are funding partners who provide funding for these projects, research institutions who provide $R \& D$ activities and non-profit sustainable energy organization who promote environmentally sustainability in communities. In these ecosystems, energy resources are owned by the community 
whilst utility companies purchase the energy from the communities. In some instances, like the case of LICMP, the utility company is responsible for providing grid management service. In both cases considered, the Clean Coalition, a nonprofit organization is key partner for project initiations. Long Island and Montecito Communities is the primary consumer of the energy produced in both CMs.

- Governance: Current literature does not provide adequate information, however there is ongoing debate as to whether these $\mathrm{CM}$ will be regulated as utility assets or products of the competitive market - or a hybrid of both? [41].

- Characteristics and relationships: Predominant characteristics are partnership between funding organizations, utilities, the communities, non-governmental organization and entities that host these installations. The key relationship between roles are distributed systems, with centralized management.

RQ2. Interaction with the power grid: These projects help to relief the power grid by facilitating energy self-sufficiency at the community level. They are usually designed such that they can provide emergency and backup services to critical infrastructure within the community during power outages. In the absence of outage, the micro-gird provides the needed power for the community.

RQ3. Role of collaboration: During power outages, the community, operators of the $\mathrm{CM}$ and emergency service providers collaborate to provide emergency power services to critical infrastructure within the community. In the absence of power outage, the community collaborate to share energy resources.

\section{Limitations of CM}

- Policy makers and regulators at various jurisdictions should consider policy changes that will enable utilities to own DER assets at least for the purpose of research and development. This will facilitate the advancement of these concepts as these utilities currently possess the capacities needed to run and test the practicability of these concepts.

- Community resistance to the mass installation of these facilities (e.g. Commercial-scale solar PVs on rooftops and parking lots) as they are perceived as aesthetic defects to the beauty of landscapes and an environmental nuisance to community settings.

- Currently in few jurisdictions, CM assets are owned by utilities (Utility 2.0, Utility of the future model) therefore community participation is limited and does not promote community sense [42].

\subsection{Peer-to-Peer Energy Sharing (P2P)}

According to [43], P2P energy sharing enables prosumers to directly trade energy with each other to achieve a win-win outcome. In [44] the authors described four different forms of P2P energy sharing networks. These are: 1) Platforms which are currently operating as proof-of-concept on a local scale and therefore target producers, prosumers and consumers; 2) P2P trading marketplace using platform-as-a-service to utility companies and retailers; 3) Cases that target prosumers and consumers on a platform with global scope; and 4) Cases that integrate two models such as local P2P platform to address producers, consumers and prosumers and also providing platform-as-a- 
service to utility companies and retailers. Both cases studied fall under the fourth category (P2P planform and platform-as-a-service):

- Case 1: Enosi ecosystem (P2P Platform and platform-as-a-service) [45],[46]

- Case 2: Pylon network (P2P Platform and platform-as-a-service) [41]

\section{Summary of Peer to Peer energy sharing}

\section{RQ1. Organization:}

- Roles and responsibilities: (i) IT partners - Provide web development and payment services; (ii) Energy partners-Management of generation and consumption; (iii) Energy Metering Oracles partners - Metering/data service Providers; (iv) Neo retailer - They provide tailor-made member management functionality; (v) Enosi platform - Platform used to trade electricity within Enosi ecosystem; (vi) GreenComputing, Smappee-Non-profit organizations that promote sustainable energy consumption and sustainable communities.

- Governance: For the Enosi ecosystem, the Enosi Decentralized Autonomous Organizations (EDAO)-has been proposed to provide ecosystem governance. In the case of Pylon Network, governance is supported through blockchain smartcontract technology.

- Characteristics and relationships: Dominant characteristic is partnerships. Key relationships are distributed systems with centralized platform for management (Offer platform-as-a-service).

RQ2. Interaction with the power grid: For the Enosi ecosystem there is 40-60\% reduction in household electricity costs. The Pylon Network provides opportunity to monetize the surplus energy by selling to the grid and also enables a reduction of payback time of DER installation up to $25 \%$. In the same network, Grid connected prosumers and large scale DER facilities are also rewarded for the energy injected into the grid.

RQ3. Role of collaborations: The trading platforms serve as coordination point to coordinate transactions and exchange of value in energy and related services. They offer platform-as-a-service and blockchain smart contracts to facilitate transactions. They do not focus on collaborations and the development of resilient communities.

\section{Limitations of Peer to peer sharing}

- The case study revealed that these energy trading platforms have weak governance structures. Other cases outside the study like [47], [48], [49], [50] shows similar trend.

- These platforms adopt blockchain as a core technology enabler to provide trustless transactions. However, literature such as [51] and [52] confirm prevailing flaws in blockchain technology which is likely to affect user confidence in terms of reliability, efficiency and safe-use.

- Currently, many jurisdictions, have challenges regulating these P2P platforms. The contention is whether to subject these prosumers to taxes and other regulations. Should they be considered as consumers or business entities? Judgment from a pending legal case at the court of Justice of the European Union that was forwarded from a Spanish court, Case C-434/15, [53] would finally answer some of these questions. 
- The focus on these trading platforms is to maximize financial gains through exchange of value in energy and its related services. Interest and benefits are usually skewed towards individual stakeholders in the ecosystem and do not promote communal interest, which invariably affect the platforms resilience.

\subsection{IEEE Smart Village (ISV)}

ISVs are IEEE Foundation Signature Programs which provide renewable energy solutions and supporting funding to members of local communities, thereby enabling them build small-scale electricity companies, and partnerships that facilitate the establishment of sustainable businesses and training programs to communities [54]. Profits are often reinvested to empower the community through learning and development programs. Currently, ISVs serves over 50,000 people in 34 villages, and is prominent in countries such as Cameroon, Haiti, Kenya, South Sudan, and many more [55]. The SunBlazer II is the ISV flagship mobile solar power unit with a $1.5 \mathrm{~kW}$ base station. This is a highly adaptable unit that integrates rechargeable battery packs and home lighting kits with an auxiliary outlet for other DC powered devices [56]. Each kit lights up two rooms and operates auxiliary $12 \mathrm{~V}$ DC loads. Each station can charge 80 battery packs every three to four days to serve an estimated 500 people [55]. The generator is configurable to other load options such as schools, churches, community centres, clinics, coolers, small businesses, and internet connectivity. The unit is designed to work with a franchise-type business model. Studied cases:

- Case 1: Haiti [57],[58]

- Case 2: India [59], [60]

\section{Summary of IEEE Smart Village}

\section{RQ1. Organization:}

- The key roles here include funding partners, local energy entrepreneurs, and nonprofit sustainable energy advocacy groups.

- Governance: Governance structures are not clearly defined, however, since these facilities are owned by local energy entrepreneurs, it could be a self-governance framework or arrangement.

- Characteristics and relationships: Key characteristics are franchising. Relationships found are distributed and stand-alone-systems.

RQ2. Relationship with the grid: These units are not connected to the grid. They are stand-alone units.

RQ3. Role of collaboration: Collaborations among stakeholders promote sustainable community businesses, capacity building through training and learning. The outcome of these collaborations results in improved livelihood and community development.

\section{Limitations of IEEE Smart Village}

- Limited generation capacity (serves few households at a time)

- Islanded units that cannot be connected to the power grid.

- Limited System scalability 


\subsection{Energy Hubs}

An energy hub is a multi-carrier energy system that integrates multiple energy technologies such as energy conversion systems, storage and network technologies. Energy hubs take many different forms and ranges from a single building to a larger geographical area. Energy hubs converts different types of energy in a hub to facilitates flexibility in energy provision. As such, energy hubs are particularly useful for enabling the integration of intermittent renewable energy sources such as solar and wind [61]. Currently this concept is being discussed within the research and academic circles. There are no real cases available yet.

\section{Research Contribution and Relationship with Collaborative Virtual Power Plants}

The main contribution of this work is that it provides grounds to implement our proposed concept of "collaborative Virtual Power Plant" [62], [63] which is an ongoing research intended to develop and implement key performance indicators that can be used to assess the global performance of RECs and their constituent prosumers when adopting a collaborative approach. In this regard, we have proposed and developed a new organizational structure for RECs by adopting knowledge and concepts from two disciplines. The two disciplines considered are: a) Collaborative Networks (CN), and b) Virtual Power Plants (VPPs). By merging concepts from these two areas, we introduce a new organizational structure that merges the functional characteristics and properties of both VPPs and CNs. In this context, our proposed CVPP ecosystem will be driven by prosumer collaborations that results in the aggregation of DER capacities of prosumers for the purpose of trading energy at the market. The proposed performance indicators are as follows:

\section{Net Economic-value Indicator.}

This indicator is intended to quantify how much value collaboration can contribute to the economic benefits of the CVPP ecosystem. The indicator will be used to determine the profitability or otherwise of the ecosystem. Furthermore, it could also be used to compare the economic performance of different energy communities and may serve as an important tool for managers of RECs at various levels of aggregation. This indicator would also be used to measure the net economic value of the global CVPP ecosystem and also per prosumer, over a defined period of time.

\section{DER-Capacity Utilization Indicator.}

This indicator is intended to measure how much collaboration can enhance efficient utilization of generation capacity of DERs within our CVPP ecosystem. In the context of the ongoing research, generation capacity is constituted of: 1 . DERs like household PV and battery storage system/electric vehicles. 2. Centralized community owned energy storage, and 3. Community owned Wind 
Turbine. The proposed indicator will be useful in determining how effective generation capacity is being utilized to achieve the objectives of the CVPP ecosystem. This indicator would be used to determine the capacity utilization of DERs at the global CVPP level and also at the prosumer level.

\section{Contribution Indicator}

This indicator is intended to measure how much each prosumer within the ecosystem contributes towards collaborations. It is expected of each prosumer to contribute towards the sale of energy to the grid. However, it is envisaged that prosumer resources are not always available due to consumption preferences and behaviour. It is therefore useful to introduce an indicator that can measure how much contribution each prosumer made over a defined period of time.

\section{Expected outcome.}

By introducing these indicators, we envisage the following:

- Determine the set of conditions that can best influence/enhance the net economic value of the CVPP ecosystem and RECs in general;

- Determine the set of conditions that can help the enhancement of DER capacity utilization in the ecosystem;

- Determine the level of prosumer contributions in the ecosystem to enable appropriate design and deployment of incentives packages that can enhance prosumer collaborations;

\section{Research approach}

The intended approach/methods are through simulations by using System Dynamics, Multi-agent System Technology and Discrete Events.

\section{Conclusion}

From the conducted study, a number of conclusions can be derived:

- RECs are promising energy sources that can help to reduce the demands on the power grid by providing off-grid power supply services to communities. Although these communities become self-sufficient in terms of energy supply, they also end up being environmentally sustainable communities in the sense that their activities promote sustainable lifestyle within the resident community.

- RECs provide an effective and less expensive alternative to the financing of electrical infrastructure which usually requires a huge initial cost of investment, therefore, making it attractive to only large utility companies.

- The concept of RECs helps to break the monopoly of big utility companies and facilitate energy democracy which is currently being advanced by grassroots activists in the United States and parts of Europe. The idea of energy democracy besides many other things also promote individuals within communities to become investors and economic beneficiaries of energy infrastructure and contribute to the governance and management of these infrastructures. 
- RECs can help mitigate the impact of natural disasters like hurricane which can knock down significant power infrastructure, leaving thousands of homes stranded and without electricity for days. RECs like Community Microgrids, Community shared Solar, etc., can help to power critical infrastructure in such circumstances since their power sources are predominantly renewable and they are also designed to be selfsustaining.

- RECs are currently empowering communities to use a bottom-up approach to advance environmental sustainability issues and promote sustainable consumption behaviors at the local community level which is more effective than traditional methods.

\section{Acknowledgements}

The authors acknowledge the contributions of the Portuguese FCT-Strategic program UID/EEA/00066/2013 for providing partial financial support for this work. Furthermore, we extend our appreciations to Ghana Educational Trust Fund (GETFund), the University of Energy and Natural Resources and UNINOVA CTS for supporting this work with their research facilities and resources.

\section{References}

[1] MACKINNON LAWRENCE et al., "Energy Cloud 4.0. Capturing Business Value through Disruptive Energy Platforms." pp. 1-46, 2018.

[2] Z. Sumic, N. Foust, E. L. Cohen, and K. Harrison, "Top 10 Trends in 2018 Driving the Utility Industry Toward a Decarbonized, Distributed, Digital and Democratized Future," no. April. pp. 1-25, 2018.

[3] L. M. Camarinha-Matos, A. I. Oliveira, F. Ferrada, and V. Thamburaj, "Collaborative services provision for solar power plants," Ind. Manag. Data Syst., vol. 117, no. 5, pp. 946-966, 2017.

[4] L. M. Camarinha-Matos, R. Fornasiero, and H. Afsarmanesh, "Collaborative Networks as a Core Enabler of Industry 4.0," in Collaboration in a Data-Rich World. PRO-VE 2017. IFIP Advances in Information and Communication Technology, 2017, vol. 507, pp. 3-17.

[5] L. M. CAMARINHA-MATOS and H. AFSARMANESH, "Collaborative networks: a new scientific discipline," J. Intell. Manuf., vol. 16, pp. 439-452, 2005.

[6] L. M. Camarinha-Matos, "Collaborative smart grids-A survey on trends," Renew. Sustain. Energy Rev., vol. 65, no. 2016, pp. 283-294.

[7] L. M. Camarinha-Matos, X. Boucher, and H. Afsarmanesh, "The Role of Collaborative Networks in Sustainability," in Collaborative Networks for a Sustainable World, IFIP Advances in Information and Communication Technology, vol. 336, Berlin, Heidelberg: Springer, 2010, pp. 1-16.

[8] L. M. Camarinha-Matos and H. Afsarmanesh, Collaborative Networks: Reference Modeling. New York: Springer Science+Business Media, LLC, 2008.

[9] J. Owyang, C. Tran, and C. Silva, "The Collaborative Economy:," Altimeter. p. 28, 2013.

[10] E. Espe, V. Potdar, and E. Chang, "Prosumer communities and relationships in smart grids: A literature review, evolution and future directions," Energies, vol. 11, no. 2528, pp. 1-24, 2018.

[11] A. J. Rathnayaka, V. M. Potdar, T. S. Dillon, and S. Kuruppu, "Formation of virtual 
community groups to manage prosumers in smart grids," Int. J. Grid Util. Comput., vol. 6, no. 1, pp. 47-56, 2015.

[12] A. J. D. Rathnayaka, V. M. Potdar, T. Dillon, O. Hussain, and S. Kuruppu, "Goaloriented prosumer community groups for the smart grid," IEEE Technol. Soc. Mag., vol. 33, no. 1, pp. 41-48, 2014.

[13] D. J. Vergados, I. Mamounakis, P. Makris, and E. Varvarigos, "Prosumer clustering into virtual microgrids for cost reduction in renewable energy trading markets," Sustain. Energy, Grids Networks, vol. 7, pp. 90-103, 2016.

[14] J. M. Zepter, A. Lüth, P. Crespo Del Granado, and R. Egging, "Prosumer integration in wholesale electricity markets: Synergies of peer-to-peer trade and residential storage,” Energy Build., vol. 184, no. 2019, pp. 163-176, 2018.

[15] M. Jarnut, S. Wermiński, and B. Waśkowicz, "Comparative analysis of selected energy storage technologies for prosumer-owned microgrids," Renew. Sustain. Energy Rev., vol. 74, no. March, pp. 925-937, 2017.

[16] T. Nagasawa et al., "Accelerating clean energy through Industry 4.0: Manufacturing the next Revolution." p. 56, 2017.

[17] C. Acosta, M. Ortega, T. Bunsen, B. P. Koirala, and A. Ghorbani, "Facilitating Energy Transition through Energy Commons: An Application of Socio-Ecological Systems Framework for Integrated Community Energy Systems," Sustainability, vol. 10, no. 366, pp. 1-15, 2018.

[18] "Neue Energien Forum Feldheim," 2018. [Online]. Available: https://neffeldheim.info/?lang=en. [Accessed: 06-Nov-2018].

[19] "Renewable energy: The Feldheim model | VoxEurop.eu: European news, cartoons and press reviews." [Online]. Available:

https://voxeurop.eu/en/content/article/4402611-feldheim-model. [Accessed: 06-Nov2018].

[20] "Wildpoldsried - Erneuerbare Energie." [Online]. Available: https://www.wildpoldsried.de/index.shtml?Energie. [Accessed: 04-Nov-2018].

[21] "IREN2 research project." [Online]. Available: https://www.energy.siemens.com/apps/features/iren2/index.html\#!/en/. [Accessed: 27Nov-2018].

[22] Siemens AG, "How a distributed energy supply works-economically and reliably." pp. $1-2,2016$.

[23] "Wildpoldsried, Germany: Go100re.net," 2014. [Online]. Available: http://www.go100re.net/properties/wildpoldsried-2/. [Accessed: 27-Nov-2018].

[24] Interstate Renewable Energy Council and The Vote Solar Initiative, "Model Rules for Shared Renewable Energy Programs," Interstate Renew. Energy Counc., pp. 1-28, 2013.

[25] M. Cleveland, "State Policies for Shared Renewable Energy," 2017. [Online]. Available: http://www.ncsl.org/research/energy/state-policies-for-shared-renewableenergy.aspx. [Accessed: 04-Dec-2018].

[26] J. Coughlin et al., "Guide to Community Solar:Utility, Private, and Nonprofit Project Development." pp. 1-76, 2012.

[27] P. Augustine, "The Time Is Right for Utilities to Develop Community Shared Solar Programs," Electr. J., vol. 28, no. 10, pp. 107-108, 2015.

[28] Westmill Solar Co-operative, "Rules of Westmill Solar Co-operative Ltd.” pp. 1-10, 2011.

[29] "Westmill Solar Co-operative." [Online]. Available: http://westmillsolar.coop/. [Accessed: 07-Nov-2018].

[30] Bristol Community Energy Limited, "Rules of Bristol Community Energy Limited." Great Britain, pp. 1-21, 2018.

[31] "Bristol Energy Cooperative - Renewable Energy." [Online]. Available: 
http://www.bristolenergy.coop/. [Accessed: 08-Nov-2018].

[32] Clean Coalation, "Clean Coalation: Community Microgrids," 2018. [Online]. Available: http://www.clean-coalition.org/our-work/community-microgrids/. [Accessed: 16-Nov-2018].

[33] PV magazine USA, "Montecito Community Microgrid Initiative will provide energy resilience to the region," 2018. [Online]. Available: https://pv-magazineusa.com/press-releases/clean-coalition-facebook-twitter-linkedin-youtube-emailsearch-our-site-skip-to-content-about-us-our-work-resources-connect-news-eventsmontecito-community-microgrid-initiative-will-provid/. [Accessed: 16-Nov-2018].

[34] Clean Coalition, "Feasibility Assessment for the Long Island Community Microgrid Project." pp. 1-116, 2016.

[35] Clean Energy Coalition, "Community Microgrid Initiative: Innovation for a Clean Energy Future." pp. 1-8, 2015.

[36] Clean Coalition, "Long Island Community Microgrid Project.” pp. 1-2, 2015.

[37] Clean Coalition, "Long Island microgrid to set stage for huge savings." pp. 1-2, 2015.

[38] S. STEEPLETON, "Montecito sets course for emergency energy independence," pp. $1-2,2018$.

[39] Clean Coalation, "Montecito Community Microgrid Initiative," 2018. [Online]. Available: http://www.clean-coalition.org/our-work/communitymicrogrids/montecito-community-microgrid-initiative/\#objectives. [Accessed: 16Nov-2018].

[40] World Business Academy, "SBR3 - Santa Barbara Microgrid - Safe Energy Project." [Online]. Available: https://safeenergyproject.org/santa-barbara-microgrid/. [Accessed: 07-Dec-2018].

[41] Utility Dive, “THE UTILTY VIEW OF MICROGRIDS.” pp. 1-12, 2014.

[42] H. K. Trabish, "How utilities can leverage their grids to integrate solar faster and cheaper," 2015. [Online]. Available: https://www.utilitydive.com/news/how-utilitiescan-leverage-their-grids-to-integrate-solar-faster-and-cheape/393540/. [Accessed: 07Dec-2018].

[43] Y. Zhou, J. Wu, and C. Long, "Evaluation of peer-to-peer energy sharing mechanisms based on a multiagent simulation framework," Appl. Energy, vol. 222, no. February, pp. 993-1022, 2018.

[44] A. Orlov and M. H. Bjørndal, "Blockchain in the Electricity Market: Identification and Analysis of Business Models," Norwegian School of Economics \& HEC Paris. pp. 1$107,2017$.

[45] Enosi, “A DISTRIBUTED ENERGY PROTOCOL: Connecting and automating energy markets with distributed ledger technology." pp. 1-37, 2018.

[46] Enosi, "Providing consumers with choice, transparency and efciency," no. April. pp. $1-39,2018$.

[47] SolarCoin, "SolarCoin: A blockchain-based solar energy incentive," https://solarcoin.org/. pp. 1-13, 2018.

[48] Consensys, "GridPlus: Welcome to the future of energy," Grid+Whitepaper v2.0. pp. $1-35,2017$.

[49] The sun exchange, "SUNEX Network Token Whitepaper: Monetizing Sunshine." pp. $1-48,2018$

[50] Vlux, "Verv VLUX Whitepaper Version 2.0: The evolution of Energy." pp. 1-55, 2018.

[51] FXCM, "What Are The Blockchain's Limitations? - FXCM," FXCM market insights, 2018. [Online]. Available: https://www.fxcm.com/insights/what-are-blockchainslimitations/. [Accessed: 27-Dec-2018].

[52] J. Berryhill, T. Bourgery, and A. Hanson, "Blockchains Unchained: Blockchain Technology and its Use in the Public Sector," OECD Work. Pap. Public Gov., no. 28, 
pp. 1-53, 2018.

[53] European Court of Justice, "Court of justice proceedings," Off. J. Eur. Union, vol. C 72, no. 2, p. C 116/2-C 116/3, 2018.

[54] D. Mackenzie, "IEEE Smart Village: Sustainable Development- A Global Mission," IEEE Power and energy society, 2018. [Online]. Available: http://sites.ieee.org/pesenews/2018/05/25/ieee-smart-village-sustainable-development-a-global-mission/. [Accessed: 21-Dec-2018].

[55] IEEE Smart Village, "The Smart Village Initiative." pp. 1-2, 2017.

[56] R. S. Larsen et al., "'Learning beyond the Light Bulb' among Least Developed Countries based on a sustainable PV solar utility model," in Proceedings of the 4th IEEE Global Humanitarian Technology Conference, GHTC 2014, pp. 106-114.

[57] IEEE Smart village, "Haiti - Integrating sustainable electricity, education, and entrepreneurial solutions to empower off-grid communities.," IEEE smart village, 2017. [Online]. Available: http://ieee-smart-village.org/communities/northamerica/haiti/. [Accessed: 28-Dec-2018].

[58] IEEE Smart village, "Empowering Off-Grid Communities." pp. 1-2, 2017.

[59] IEEE Smart Village, "India - Integrating sustainable electricity, education, and entrepreneurial solutions to empower off-grid communities," IEEE smart village, 2017. [Online]. Available: http://ieee-smart-village.org/communities/asia/india/. [Accessed: 28-Dec-2018].

[60] IEEE Smart village, “About IEEE Smart Village - IEEE Smart Village,” IEEE Smart village, 2017. [Online]. Available: http://ieee-smart-village.org/about/. [Accessed: 28Dec-2018].

[61] Energy Hub, "Future Energy Efficient Buildings \& Districts," 2018. [Online]. Available: http://www.sccer-feebd.ch/research/energy-hub-definition-advantages-andchallenges/. [Accessed: 17-Nov-2018].

[62] K. O. Adu-Kankam and L. M. Camarinha-Matos, "Towards Collaborative Virtual Power Plants: Trends and convergence," Sustain. Energy, Grids Networks, vol. 16, no. December 2018, pp. 217-230, 2018.

[63] K. O. Adu-Kankam and L. M. Camarinha-Matos, "Towards Collaborative Virtual Power Plants," in Technological Innovation for Resilient System, 9th IFIP WG 5.5/SOCOLNET Advanced Doctoral Conference on Computing, Electrical and Industrial Systems, DoCEIS 2018 Costa de Caparica, Portugal, May 2-4, 2018 Proceedings, 2018, pp. 28-39. 